\section{JURNAL EKONOMI EFEKTIF}

ISSN : $2622-8882$, E-ISSN : 2622-9935

Jurnal Ekonomi Efektif, Vol. 3, No. 2, Januari 2021 @Prodi Manajemen Fakultas Ekonomi Universitas Pamulang

\title{
PENGARUH BIAYA PENDIDIKAN MURAH DAN KEPUASAN AKADEMIK MAHASISWA TERHADAP KEUNGGULAN BERSAING PADA UNIVERSITAS PAMULANG
}

\author{
Yogi Ibrahim \\ Universitas Pamulang, Tangerang Selatan, Banten, Indonesia \\ dosen02572@unpam.ac.id
}

Manuskrip: Sept-2020; Ditinjau: Okt-2020; Diterima: Nov-2020; Online: Jan-2021; Diterbitkan: Jan-2021

\begin{abstract}
ABSTRAK
Penelitian ini bertujuan untuk mengetahui pengaruh Biaya Pendidikan Murah dan Kepuasan Akademik Mahasiswa secara parsial maupun secara bersama-sama terhadap Keunggulan Bersaing. Penelitian ini menggunakan metode kuantitatif dengan teknik survei. Instrumen pengumpul data yang digunakan adalah kuesioner tertutup dengan skala likert. Penelitan ini menggunakan sampel acak dengan jumlah responden sebanyak 88 mahasiswa pascasarjana magister manajemen. Data yang diperoleh dari penelitian ini dianalisis dengan menggunakan metode statistik Regresi Linear Berganda dengan bantuan program SPSS 24.00 for windows. Hasil dari penelitian ini menunjukkan bahwa terdapat pengaruh yang kuat, positif dan signifikan biaya pendidikan murah (X1) dan kepuasan akademik mahasiswa (X2) secara bersama-sama terhadap keunggulan bersaing (Y), koefisien determinasi korelasi ganda diperoleh 0,552 dengan persamaan regresi ganda $\mathrm{Y}=31,062+0,941 \mathrm{X} 1+0,449 \mathrm{X} 2$.
\end{abstract}

\section{Kata Kunci: Biaya Pendidikan, Kepuasan Mahasiswa, Keunggulan Bersaing.}

\section{ABSTRACT}

This study aims to determine the effect of Cheap Education and Student Academic Satisfaction partially and jointly on Competitive Advantage. This study uses quantitative methods with survey techniques. The data collection instrument used was a closed questionnaire with a Likert scale. This research uses a random sample with the number of respondents as many as 88 postgraduate masters management students. The data obtained from this study will be analyzed using statistical methods with the SPSS version 24.00 for Windows. The results of this study indicate that positive and significant effect of cheap education costs (X1) and student academic satisfaction (X2) together on competitive advantage $(Y)$, multiple reverse determination coefficients were obtained by 0.552 with multiple regression equations result $Y=31.062+0.941 X 1+0.449 X 2$.

Keywords: Education Costs, Student Satisfaction, Competitive Advantage. 


\section{PENDAHULUAN}

\section{A. Latar Belakang Masalah}

Masalah pendidikan adalah masalah besar dan terkait erat dengan seluruh masyarakat maka keikut-sertaan masyarakat sangat diharapkan. Namun masalah pendidikan juga tidak dapat sepenuhnya dilepaskan begitu saja kepada masyarakat. Pemerintah harus memberikan bimbingan dan pedoman yang baku, berorientasi kepada fleksibilitas tidak kaku, agar dapat dijadikan acuan bersama untuk dapat maju.

Keluaran (output) secara kualitas dan kuantitas pendidikan akan sangat tergantung pada proses, input yang terdiri atas visi, misi, dosen, calon mahasiswa, kurikulum dan sumber belajar, pembelajarannya, sehingga nilai manfaat (outcome) nya bagi stake holder akan sangat tergantung pada kualitas output nya. Dengan demikian, hal tersebut akan dapat diimplikasikan sebagai perwujudan hukum kausal, dan dampaknya dapat dilihat pada aktualisasi kondisi hasil pendidikan saat ini.

Dunia Pendidikan merupakan suatu sarana untuk meningkatkan kualitas Sumber daya Manusia (SDM) agar memiliki daya saing yang wajar sesuai dengan kemampuan akademik atau professional. Namun demikian dapat dikatakan bahwa, Pendidikan tinggi yang diselenggarakan akan sangat menentukan bagi keberhasilan suatu bangsa dan Negara untuk mencapai keunggulan bersaing secara terus-menerus. Dalam hubungan ini Perguruan Tinggi sebagai sarana alternatif dalam rangka meningkatkan kualitas (SDM) dihadapkan kepada mekanisme keterbukaan pasar, sehingga persaingan lebih terjadi di Perguruan Tinggi.

Bauran pemasaran yang digunakan adalah analisis konsep 7P yang terdiri dari 4P Tradisional, yaitu jasa Perguruan Tinggi Swasta, harga jasa perguruan tinggi/biaya Pendidikan, lokasi perguruan tinggi dan Promosi perguruan tinggi, ditambah dengan 3P khusus untuk pemasaran jasa, yaitu sumber daya manusia di Perguruan Tinggi, bukti fisik/sarana dan prasarana Perguruan Tinggi dan proses manajemen layanan Peguruan Tinggi, ketujuh unsur dalam bauran pemasaran tersebut perlu dirancang sedemikian rupa sehingga dapat memuaskan mahasiswa sebagai pelanggan jasa Pendidikan.

Dengan mengunakan ketujuh elemen didalam bauran pemasaran tersebut, maka di harapkan penelitian dapat mengetahui sampai sejauh mana pengaruh ketujuh elemen tersebut terhadap penciptaan kepuasan mahasiswa, setelah kita mencoba untuk menentukan faktor-faktor yang mempengaruhi kepuasan pelanggan yang dalam penelitian ini adalah mahasiswa, maka sudah seharusnya kita juga mengkaji definisi mahasiswa sebagai pelanggan dalam konteks dunia Pendidikan, pengertiaan ini menjadi sangat penting mengigat akan tejadi suatu ambiguitas dalam memperlakukan mahasiswa sebagai pelanggan.

Berbicara masalah kepuasan maka senada dengan itu Sheila Kessier (1996) menyatakan bahwa, kepuasan mahasiswa telah menjadi suatu bagian penting dari strategi marketing, dan memiliki kekuatan yang lebih hebat dari pada sebuah iklan. Data kepuasan mahasiswa memberikan sinyal-sinyal akan terjadi masalah, dengan segera. Hal tersebut dapat terlihat pada penurunan pendapatan dan keuntungan.

Pelanggan dalam penelitian ini dibatasi hanya pada mahasiswa saja, dengan dasar pemikiran bahwa pelayanan yang diberikan dari jasa Pendidikan Tinggi secara langsung dapat dirasakan oleh para mahasisiwa tersebut. Pada suatu sisi, mahasiswa akan diposisikan sebagai mahasiswa yang harus dilayani sedemikian rupa agar kepuasan tercipta karena pelayanan, sedangkan sebagai konsumen secara tidak langsung akan menjadi marketing bagi konsumen yang loyal. Untuk itu, perlu dilakukan penelitian yang mendalam mengenai faktor-faktor apa saja yang dapat mempengaruhi tingkat kesetiaan mahasiswa terhadap suatu produk, yang dalam penelitian ini adalah jasa Pendidikan 
Tinggi.

Dewasa ini semakin diyakini bahwa kunci utama untuk memenangkan persaingan adalah memberikan nilai dan kepuasan kepada pelanggan melalui penyampaian produk dan jasa berkualitas dengan harga bersaing (Rahmayanty, 2010: 6). Mahasiswa yang masuk sebuah perguruan tinggi tentu mempunyai banyak harapan seperti adanya kesempatan lapangan kerja, pengembangan karir, dan adanya kepuasan, kesenangan, dan kebanggaan sebagai mahasiswa di perguruan tinggi tersebut (Bowen dalam Alma, 2005: 69 dalam Novianti, 2012). Dalam satu angkatan, sering terjadi mahasiswa yang tidak melanjutkan perkuliahan sebelum selesai studi. Hal ini menyebabkan pengurangan jumlah mahasiswa pada program pascasarjana Universitas Pamulang. Dari segi proses belajar mengajar di dalam kelas, mahasiswa mengeluhkan adanya beberapa dosen yang tidak kredibel dalam bidang yang diajarkan, strategi pembelajaran yang monoton dan kurang variasi. Oleh karena itu, perlu adanya evaluasi mengenai proses belajar mengajar yang penting bagi peningkatan mutu universitas.

Dalam hal pelayanan, Universitas Pamulang juga berusaha memberikan layanan yang prima bagi para mahasiswanya, meskipun demikian mahasiswa masih berpendapat terdapatnya layanan yang kurang maksimal yang diberikan kepada mahasiswa program pascasarjana Universitas Pamulang, terutama dalam penyampaian informasi kewajiban keuangan maupun persoalan penjadwalan kuliah yang terkadang informasinya simpang siur kepada para mahasiswa.

Dengan dikenalnya suatu Peguruan Tinggi di masyarakat karena kemampuan dalam memberikan pelayanan yang sangat baik bagi mahasiswa dan juga karena prestasiprestasi kualitas yang dimiliki, maka hal ini dapat meningkatkan loyalitas mahasisiwa positif dari Perguruan Tinggi. Jika suatu Perguruan Tinggi dapat terus menerus, maka hal tersebut sekaligus dapat membentuk image suatu Perguruan Tinggi sebagai pusat unggulan.

Dalam berbagai persaingaan pada dasarnya setiap organisasi yang bersaing dalam suatu lingkungan industri mempunyai keinginan untuk dapat lebih unggul dibandingkan pesaingnya. Perguruan Tinggi Universitas Pamulang juga memilki cita-cita yang besar ingin jadi perguruan tinggi yang mampu merambah pasar nasional dan pasar internasional.

Universitas Pamulang dari sisi harga sudah memilki keunikan yang unggul, gedung yang megah, besar dan milik sendiri. Akan tetapi dari sisi proses produksi pendidikan perlu ditingkatkan agar memilki keunggulan yang lebih lengkap dan unik, sehingga diharapkan dapat diterima di dunia kerja dan memberikan Brand Image yang positif tentang Universitas Pamulang.

Keunikan lainnya perlu diciptakan dengan segala kreatifitas seluruh sivitas akademika Universitas Pamulang, seperti adanya keunikan yang jarang dijumpai di perguruan tinggi yang lain, tidak mudah ditiru oleh pesaing, dan tidak mudah digantikan. Sehingga keunikan itu benar-benar menjadi pembeda dari pesaing, yang dapat dijadikan sebuah diferensiasi dalam memasarkan produk-produk lembaga pendidikan Universitas Pamulang itu sendiri.

Berdasarkan pemikiran dan fakta empiris yang telah disampaikan tersebut, maka penelitian ini akan melakukan kajian secara mendalam tentang Pengaruh Biaya Pendidikan Murah Dan Kepuasan Akademik Mahasiswa Terhadap Keunggulan Bersaing Pada Universitas Pamulang, menjadi tema penelitian yang penulis teliti. 


\section{B. Rumusan Masalah}

1. Apakah terdapat pengaruh yang positif dan signifikan biaya pendidikan murah terhadap keunggulan bersaing program Pascasarjana Magister Manajemen Universitas Pamulang?

2. Apakah terdapat pengaruh yang positif dan signifikan kepuasan akademik mahasiswa terhadap keunggulan bersaing program Pascasarjana Magister Manajemen Universitas Pamulang?

3. Apakah terdapat pengaruh yang positif dan signifikan biaya pendidikan murah dan kepuasan akademik mahasiswa secara bersama-sama terhadap keunggulan bersaing program Pascasarjana Magister Manajemen Universitas Pamulang?

\section{Tujuan Penelitian}

1. Untuk mengetahui seberapa besar pengaruh biaya pendidikan murah terhadap keunggulan bersaing program Pascasarjana Magister Manajemen Universitas Pamulang

2. Untuk mengetahui seberapa besar pengaruh kepuasan akademik mahasiswa terhadap keunggulan bersaing program Pascasarjana Magister Manajemen Universitas Pamulang.

3. Untuk mengetahui seberapa besar pengaruh biaya pendidikan murah dan kepuasan akademik mahasiswa secara bersama-sama terhadap keunggulan bersaing program Pascasarjana Magister Manajemen Universitas Pamulang.

\section{METODE PENELITIAN}

\section{Populasi}

Populasi dalam penelitian ini adalah seluruh Mahasiswa Program Magister Manajemen Strata 2 periode 2016-2017 di Universitas Pamulang., sebanyak 680 orang.

\section{Sampel}

Perwakilan populasi yang dijadikan sampel adalah Mahasiswa Program Magister Manajemen Strata 2 Semester 1 sampai semester 4. Karena jumlah populasi 680 mahasiswa, maka penarikan sampel dalam penelitian ini mengunakan sampel secara acak (Random Sampling) sedangkan teknik pengambilan sampel menggunakan rumus dari Slovin dalam Riduan (2007) dapat menggunakan rumus sebagai berikut :

$$
\begin{aligned}
& n=\frac{N}{N \cdot d^{2}+1} \\
& n=\frac{680}{7,8} \\
& n=87,18 \text { Responden dibulatkan jadi } 88 \text { Responden. }
\end{aligned}
$$

\section{Jenis Penelitian}

Jenis penelitian yang dipakai adalah asosiatif, dimana tujuannya adalah untuk mengetahui mencari keterhubungan antara variabel $\mathrm{x}$ dan variabel $\mathrm{y}$

\section{Metode Analisis Data}

Dalam menganalisis data digunakan uji instrumen, uji asumsi klasik, regresi, koefisien determinasi dan uji hipotesis.

\section{HASIL PENELITIAN DAN PEMBAHASAN}

\section{Uji Hipotesis Pertama dengan Uji Parsial (Uji t)}

Untuk menguji apakah terdapat pengaruh positif variabel biaya pendidikan murah dan kepuasan akademik mahasiswa secara parsial/individual terhadap variabel 
keunggulan bersaing, maka digunakan uji Statistik t (uji t). Dengan menggunakan taraf signifikansi 5\% $(0,05)$ dan derajat kebebasan $(\mathrm{dk})$ dengan rumus : $\mathrm{dk}=\mathrm{n}-\mathrm{k}$, dimana $\mathrm{n}$ adalah jumlah responden dan $\mathrm{k}$ adalah jumlah variabel yang diteliti.

Tabel 1 Model Regresi Sederhana Biaya Pendidikan Murah (X1) Terhadap Keunggulan

Bersaing (Y)

Coefficients $^{\mathrm{a}}$

\begin{tabular}{llc|c|c|c|c} 
& & \multicolumn{5}{c}{} \\
Model & & \multicolumn{2}{c}{$\begin{array}{c}\text { Unstandardized Coefficients } \\
\text { B }\end{array}$} & $\begin{array}{c}\text { Standardized } \\
\text { Coefficients }\end{array}$ & & \\
\hline 1 & & B & Std. Error & Beta & t & Sig. \\
\hline & BPM & $\mathbf{4 4 . 3 8 0}$ & 5.752 & & 7.715 & .000 \\
\hline
\end{tabular}

a. Dependent Variable: KEUB

Sumber: Data Primer yang telah diolah (2017).

Tabel 2 Koefisien Determinasi Biaya Pendidikan Murah (X1) Terhadap Keunggulan Bersaing (Y)

\begin{tabular}{ll|r|r|r} 
& & \multicolumn{2}{c}{ Model Summary } \\
Model & R & R Square & $\begin{array}{c}\text { Adjusted R } \\
\text { Square }\end{array}$ & $\begin{array}{c}\text { Std. Error of the } \\
\text { Estimate }\end{array}$ \\
\hline 1 & $\mathbf{. 6 9 5}^{\mathbf{a}}$ & $\mathbf{. 4 8 3}$ & .477 & 4.764 \\
\hline
\end{tabular}

a. Predictors: (Constant), BPM

b. Dependent Variable: KEUB

Sumber: Data Primer yang telah diolah (2017).

Dapat diuraikan dari output data tabel-tabel di atas dengan hasil sebagai berikut:

a. Model Regresi Sederhana yang diperoleh : $Y=44,380+1,318 X 1$

b. Nilai Koefisien Korelasi $(\mathrm{R})=0,695$ sedangkan nilai Koefisien Determinasinya (R2) $=0,483$

c. Nilai thitung sebesar 8,966 dengan signifikansi t sebesar 0,000

d. Karena thitung $>$ ttabel $(8,966>1,988)$ dan t signifikansi $0.000<\mathrm{t}(0,000<0,05)$

Maka H0 ditolak dan H1 diterima, sehingga dengan nilai thitung yang lebih besar dari ttabel menunjukan bahwa biaya pendidikan murah (X1) mempunyai pengaruh positif dan signifikan terhadap keunggulan bersaing (Y).

\section{Uji Hipotesis Kedua dengan Uji Parsial (Uji t)}

Hasil perhitungan Uji t untuk variabel kepuasan akademik mahasiswa (X2) terhadap keunggulan bersaing (Y) dapat dilihat pada tabel berikut.

Tabel 3 Model Regresi Sederhana Kepuasan Akademik Mahasiswa (X2) Terhadap Keunggulan Bersaing (Y)

\begin{tabular}{|c|c|c|c|c|c|c|}
\hline \multirow{3}{*}{\multicolumn{2}{|c|}{ Model }} & \multicolumn{2}{|r|}{ Coefficients $^{\mathbf{a}}$} & \multicolumn{3}{|l|}{ 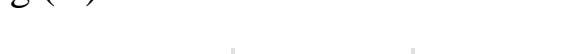 } \\
\hline & & \multicolumn{2}{|c|}{ Unstandardized Coefficients } & \multirow{2}{*}{$\begin{array}{c}\text { Standardized } \\
\text { Coefficients } \\
\text { Beta } \\
\end{array}$} & \multirow[b]{2}{*}{$\mathbf{t}$} & \multirow[b]{2}{*}{ Sig. } \\
\hline & & B & Std. Error & & & \\
\hline \multirow[t]{2}{*}{1} & (Constant) & 50.398 & 10.428 & & 4.833 & .000 \\
\hline & KAM & 1.485 & .341 & .425 & 4.357 & .000 \\
\hline
\end{tabular}

a. Dependent Variable: KEUB

Sumber: Data Primer yang telah diolah (2017).

Tabel 4.Koefisien Determinasi Kepuasan Akademik Mahasiswa (X2) Terhadap Keuanggulan Bersaing (Y)

\begin{tabular}{ll|r|c|r|} 
& & \multicolumn{2}{|c}{ Model Summary } \\
Model & $\mathbf{R}$ & R Square & $\begin{array}{c}\text { Adjusted R } \\
\text { Square }\end{array}$ & $\begin{array}{c}\text { Std. Error of the } \\
\text { Estimate }\end{array}$ \\
\hline 1 & $\mathbf{. 4 2 5}^{\mathbf{a}}$ & $\mathbf{. 1 8 1}$ & .171 & 5.998 \\
\hline
\end{tabular}

a. Predictors: (Constant), KAM 
Dapat diuraikan dari output data tabel-tabel di atas dengan hasil sebagai berikut:

a. Model Regresi Sederhana yang diperoleh : Y= 50,398+1,485X2

b. Nilai Koefisien Korelasi $(\mathrm{R})=0,425$ sedangkan nilai Koefisien Determinasinya (R2) $=0,181$

c. Nilai thitung sebesar 4,357 dengan signifikansi t sebesar 0,000

d. Karena thitung $>$ ttabel $(4,357>1,988)$ dan $t$ signifikansi $0.000<t(0,000<0,05)$

Maka H0 ditolak dan $\mathrm{H} 1$ diterima, sehingga dengan nilai thitung yang lebih besar dari ttabel menunjukkan bahwa kepuasan akademik mahasiswa (X2) mempunyai pengaruh positif dan signifikan terhadap keunggulan bersaing (Y).

\section{Uji Hipotesis Ketiga dengan Uji Simultan (Uji F).}

Digunakan uji Statistik F (uji F) untuk menguji apakah terdapat pengaruh positif variabel biaya pendidikan murah dan kepuasan akademik mahasiswa secara simultan/bersama-sama terhadap variabel keunggulan bersaing, dengan taraf signifikansi $5 \%(0,05)$ dan derajat kebebasan $(\mathrm{dk})$ dengan rumus : $\mathrm{dk}=\mathrm{n}-\mathrm{k}-1$, dimana $\mathrm{n}$ adalah jumlah responden dan $\mathrm{k}$ adalah jumlah variabel yang diteliti. Kemudian membandingkan Fhitung dengan Ftabel dengan kriteria :

Jika Fhitung $>$ Ftabel, $(\alpha, \mathrm{dk})$, berarti $\mathrm{H0}$ ditolak dan H1 diterima.

Jika Fhitung $<$ Ftabel $(\alpha, \mathrm{dk})$, berarti H0 diterima dan H1 ditolak.

Dimana derajat kebebasan (dk) adalah :

$$
\begin{aligned}
\mathrm{dk} & =\mathrm{n}-\mathrm{k}-1 \\
& =88-2-1 \\
& =85
\end{aligned}
$$

Ftabel $=\mathrm{F}(\alpha ; \mathrm{dk})$

$=(0,05 ; 95$ Angka derajat kebebasan tersebut pada tingkat kesalahan 5\%).

$=2,71$

Untuk mengetahui hasil uji signifikansi secara bersama-sama dengan menggunakan uji F, dapat di lihat pada tabel di bawah ini:

\begin{tabular}{|c|c|c|c|c|c|c|}
\hline \multirow[b]{3}{*}{ Mod } & & & Coemctist & \multirow{3}{*}{$\begin{array}{c}\text { Standardized } \\
\text { Coefficients } \\
\text { Beta }\end{array}$} & \multirow{3}{*}{$\mathrm{t}$} & \\
\hline & & \multicolumn{2}{|c|}{$\begin{array}{l}\text { Unstandardized } \\
\text { Coefficients }\end{array}$} & & & \multirow{2}{*}{ Sig. } \\
\hline & & B & Std. Error & & & \\
\hline \multirow[t]{3}{*}{1} & (Constant) & 39.277 & 8.444 & & 4.651 & .000 \\
\hline & BPM & 1.241 & .174 & .655 & 7.127 & .000 \\
\hline & KAM & .265 & .321 & .076 & .827 & .411 \\
\hline
\end{tabular}

Tabel 5 Hasil Uji Regresi Berganda X1 dan X2 Terhadap Y

\section{Coefficients $^{\mathrm{a}}$}

a. Dependent Variable: KEUB

\begin{tabular}{|c|c|c|c|c|c|c|}
\hline \multirow{2}{*}{\multicolumn{2}{|c|}{ Model }} & \multicolumn{4}{|c|}{ ANOVA $^{\mathbf{a}}$} & \multirow[b]{2}{*}{ Sig. } \\
\hline & & Sum of Squares & df & Mean Square & $\mathbf{F}$ & \\
\hline 1 & Regression & 1840.076 & 2 & 920.038 & 40.385 & $.000^{1}$ \\
\hline & Residual & 1936.424 & 85 & 22.781 & & \\
\hline & Total & 3776.500 & 87 & & & \\
\hline
\end{tabular}

Sumber: Data Primer yang telah diolah (2017)

Tabel 6. Hasil Uji Signifikansi Simultan (Uji F)

a. Dependent Variable: KEUB

b. Predictors: (Constant), BPM,KAM

Sumber: Data Primer yang telah diolah (2017)

Tabel 7. Koefisien Determinasi X1 dan X2 Terhadap Keunggulan Bersaing (Y) Model Summary ${ }^{\mathrm{b}}$

\begin{tabular}{lr|r|r|r} 
Model & R & R Square & \multicolumn{1}{|c|}{$\begin{array}{c}\text { Adjusted R } \\
\text { Square }\end{array}$} & $\begin{array}{l}\text { Std. Error of the } \\
\text { Estimate }\end{array}$ \\
\hline 1 & $\mathbf{. 6 9 8}^{\mathbf{a}}$ & $\mathbf{. 4 8 7}$ & .475 & 4.773 \\
\hline
\end{tabular}


a. Predictors: (Constant), BPM, KAM

b. Dependent Variable: KEUB

Sumber: Data Primer yang telah diolah (2017)

Dari output data tabel di atas diperoleh hasil sebagai berikut:

a. Model Regresi Linier Berganda yang diperoleh adalah: $\mathrm{Y}=$ $39,277+1,241 \mathrm{X} 1+0,265 \mathrm{X} 2$

b. Nilai Koefisien Korelasi $(\mathrm{R})=0,698$ sedangkan nilai Koefisien Determinasinya (R2) $=0,487$

c. Nilai Fhitung sebesar 40,385 dengan signifikansi sebesar 0,000

d. Karena Fhitung $>$ Ftabel $(40,385>2,71)$ dan signifikansi $<0,05(0,000<0,05)$

Maka H0 ditolak dan H1 diterima, sehingga dapat disimpulkan bahwa terdapat pengaruh positif dan signifikan antara biaya pendidikan murah (X1) dan kepuasan akademik mahasiswa (X2) secara bersama-sama terhadap keunggulan bersaing (Y).

\section{PEMBAHASAN HASIL PENELITIAN}

\section{Pengaruh Biaya Pendidikan Murah (X1) terhadap Keunggulan Bersaing (Y)}

a. Berdasarkan pengolahan data diperoleh model hubungan pengaruh dalam bentuk persamaan regresi linier sederhana $\mathrm{Y}=45,860+1,136 \mathrm{X} 1$

b. Persamaan tersebut memberikan informasi bahwa Konstanta sebesar 45,860 dapat dikatakan bahwa tanpa variabel biaya pendidikan murah, besarnya nilai keunggulan bersaing tetap terbentuk sebesar 45,860 dan setiap peningkatan satu unit biaya pendidikan murah akan dapat mengakibatkan peningkatan keunggulan bersaing sebesar 1,136 .

c. Kemudian hasil analisis korelasi sederhana antara biaya pendidikan murah dan keunggulan bersaing diperoleh ryx $1=0,699$ yang memiliki makna bahwa tingkat pengaruh biaya pendidikan murah terhadap keunggulan bersaing adalah kuat.

d. Uji t signifikan menghasilkan thitung $=9,064>$ ttabel $=1.988$, sehingga koefisien korelasi tersebut signifikan. Untuk konteks ini berarti biaya pendidikan murah semakin baik, semakin baik juga keunggulan bersaing dengan tingkat pengaruh kuat.

e. Karena nilai koefisien deteminasinya (Adjusted R2) sebesar 0,483 maka kontribusi variabel biaya pendidikan murah mempengaruhi keunggulan bersaing sebesar 48,3\%. Hal ini menunjukkan bahwa variabel biaya pendidikan murah berpengaruh positif dan signifikan terhadap keunggulan bersaing..

\section{Pengaruh Kepuasan Akademik Mahasiswa (X2) terhadap Keunggulan Bersaing} (Y)

a. Hasil pengolahan data diperoleh model pengaruh dalam bentuk persamaan regresi linier sederhana $\mathrm{Y}=57,098+0,802 \mathrm{X} 2$

b. Persamaan tersebut memberikan informasi bahwa Konstanta sebesar 57,098 dapat dikatakan bahwa tanpa variabel kepuasan akademik mahasiswa, besarnya nilai keunggulan bersaing tetap terbentuk sebesar 57,098 dan setiap peningkatan satu unit kepuasan akademik mahasiswa akan dapat mengakibatkan peningkatan keunggulan bersaing sebesar 0,802 .

c. Kemudian hasil analisis korelasi sederhana antara kepuasan akademik mahasiswa dan keunggulan bersaing diperoleh ryx $2=0,530$ yang memiliki makna bahwa tingkat pengaruh kepuasan akademik mahasiswa terhadap keunggulan bersaing adalah cukup kuat.

d. Uji t signifikan menghasilkan thitung $=5,800>$ ttabel $=1.988$, sehingga koefisien korelasi tersebut signifikan. Untuk konteks ini berarti kepuasan akademik mahasiswa semakin baik, semakin baik juga keunggulan bersaing dengan tingkat 
pengaruh cukup kuat.

e. Karena nilai koefisien deteminasinya (Adjusted R2) sebesar 0,273 maka kontribusi variabel kepuasan akademik mahasiswa mempengaruhi keunggulan bersaing sebesar 27,3\%. Hal ini menunjukan bahwa variabel kepuasan akademik mahasiswa berpengaruh positif dan signifikan terhadap keunggulan bersaing.

\section{Pengaruh Biaya Pendidikan Murah (X1) dan Kepuasan Akademik Mahasiswa (X2) secara Simultan terhadap Keunggulan Bersaing (Y)}

a. Berdasarkan pengolahan data diperoleh model hubungan pengaruh dalam bentuk persamaan regresi linier berganda :

b. $\mathrm{Y}=31,062+0,941 \mathrm{X} 1+0,449 \mathrm{X} 2$

c. Persamaan tersebut memberikan informasi bahwa Konstanta sebesar -31,062 dapat dikatakan bahwa tanpa variabel biaya pendidikan murah (X1) dan kepuasan akademik mahasiswa (X2), besarnya nilai keunggulan bersaing (Y) tetap terbentuk sebesar 31,062.

d. Kemudian hasil analisis korelasi berganda antara biaya pendidikan murah (X1) dan kepuasan akademik mahasiswa (X2) terhadap keunggulan bersaing (Y) diperoleh ryx $1 \times 2=0,750$ yang memiliki makna bahwa tingkat pengaruh kedua variabel independen secara simultan terhadap keunggulan bersaing adalah kuat.

e. Uji signifikan menghasilkan Fhitung $=54,632>$ Ftabel $=$ 2,71 sehingga koefisien korelasi tersebut positif dan signifikan. Untuk konteks ini berarti kedua variabel independen secara simultan semakin baik, semakin baik juga keunggulan bersaing dengan tingkat pengaruh kuat.

f. Kontribusi kedua variabel independen secara simultan mempengaruhi keunggulan bersaing sebesar 55,2\%, karena nilai koefisien deteminasinya (Adjusted R2) sebesar 0,552. Hal ini menunjukan bahwa variabel biaya pendidikan murah (X1) dan kepuasan akademik mahasiswa (X2) secara bersama-sama berpengaruh positif dan signifikan terhadap keunggulan bersaing (Y).

\section{PENUTUP}

\section{Kesimpulan}

a. Terbukti Biaya Pendidikan Murah (X1) berpengaruh positif dan signifikan terhadap Keunggulan Bersaing (Y). Biaya Pendidikan Murah (X1) memberikan kontribusi terhadap Keunggulan Bersaing (Y) sebesar 48,3\%. Dengan demikian sisanya sebesar $51,7 \%$ dipengaruhi oleh variabel lain.

b. Terbukti Kepuasan Akademik Mahasiswa (X2) berpengaruh positif dan signifikan terhadap Keunggulan Bersaing (Y). Kepuasan Akademik Mahasiswa (X2) memberikan kontribusi sebesar 27,3\%. Dengan demikian sisanya sebesar $73,7 \%$ dipengaruhi oleh variabel lain.

c. Terbukti secara simultan, Biaya Pendidikan Murah (X1), dan Kepuasan Akademik Mahasiswa (X2) secara bersama-sama memberikan pengaruh terhadap Keunggulan Bersaing (Y), dengan signifikan sebesar $55,2 \%$, sehingga sisanya sebesar $44,8 \%$ dipengaruhi oleh variabel lain yang tidak diteliti dalam penelitian ini.

\section{Saran}

a. Pada variabel Biaya Pendidikan Murah (X1) didapatkan skor terendah pada pernyataan: "Biaya Pendidikan Murah di Pascasarjana UNPAM sangat bersaing dari PTS lain" Saran yang diberikan ke pihak Manajemen Universitas Pamulang adalah sebaiknya dilakukan penawaran-penawaran dalam hal metode pembayaran yang lebih 
meringankan mahasiswa pascasarjana dalam menunaikan pembayaran biaya pendidikannya, seperti bila seluruh biaya akan dibayar tunai di awal semester maka akan ada pengurangan nilai beban biaya.

b. Pada variabel Kepuasan Akademik Mahasiswa (X2) didapatkan skor terendah pada pernyataan: "Saya puas terhadap penawaran harga/kewajiban keuangan bagi para mahasiswa program pascasarjana Universitas Pamulang" Saran yang disampaikan agar diupayakan beban biaya pendidikan untuk pascasarjana sebisa mungkin ditekan menjadi lebih murah lagi dari yang sudah berjalan saat ini.

c. Pada variabel Keunggulan Bersaing (Y) didapatkan skor terendah kedua pada pernyataan: "UNPAM memiliki Sumber Daya Manusia (Pimpinan Jajaran Rektorat) yang berkualitas". Saran yang disampaikan ke Manajemen agar dilakukan peningkatan profesionalisme bagi sumberdaya manusia yang telah ada dengan pelatihan-pelatihan dan semacamnya.

\section{DAFTAR PUSTAKA}

Abbas, S. (2008). Manajemen Perguruan Tinggi: Beberapa Catatan, Aceh: Prenada Media Group.

Akbar, I. R. (2018). Analisis Kebijakan Kepala Sekolah Dalam Upaya Meningkatkan Kompetensi Guru (Study Kasus Pada SMK Muhammadiyah Parung). Tesis. Universitas Pamulang

Alma, B. (2005). Pemasaran Stratejik Jasa Pendidikan, Bandung: Penerbit Alfabeta,

Arikunto Suharsimi, 2000. "Manajemen Penelitian", Rineka Cipta, Jakarta..

Basu Swastha Dharmmesta dan T. Hani Handoko, 2004,"Manajemen Pemasaran, Analisa perilaku konsumen", BPEE Yogyakarta.

Buttle, F. (2007). Customer Relationship Management Concepts and Tools, Jakarta: Bayumedia Publishing.

Dahlan Abdullah, Mirna Dewi, Yuliwati, Ahmad khoiri, Cut Ita Erliana, (2020). Pengukuran efisiensi pendidikan pesantren di Kota Lhokseumawe menggunakan metode data envelopment analysis. Sefa Bumi Persada: Aceh Indonesia

Depdikbud. (2002). Kamus Besar Bahasa Indonesia, Jakarta: Balai Pustaka.

Elfindri. (2011). Pendidikan Sebagai Barang Ekonomi, Bandung: Lubuk Agung.

Ghozali, I. (2002). Aplikasi Analisis Multivariate dengan Program SPSS, Edisi I, Semarang: Badan Penerbit Universitas Diponegoro.

Hasibuan, J. J., dan Moedjiono. (2008). Proses Belajar Mengajar. Bandung: PT Remaja Rosdakarya Offset.

Hassan, F. dan Sukra, Y. (2007). Pendidikan Tinggi dalam Perspektif Sejarah dan Perkembangannya di Indonesia, Jakarta: Penerbit Universitas Indonesia.

http://junaidichaniago.wordpress.com

http://www.unpam.ac.id

IKAPI. (2010). Himpunan Peraturan Perundang-undangan Pengelolaan dan Penyelenggaraan Pendidikan, Bandung: Fokus Media.

Jonker, J., Pennink, B. J. W., dan Wahyuni, S. (2011). Metodologi Penelitian, Jakarta: Penerbit Salemba Empat.

Kelvin, (2015), "Analisis Pengaruh Promosi, Biaya Studi, Fasilitas Perkuliahan, dan Kualitas Pelayanan Terhadap Keputusan Mahasiswa untuk Kuliah di Sekolah Tinggi Teknik Surabaya", Jurnal Manajemen Kinerja, Vol. 4 Nomor 1, diunduh Oktober 2017, https://jurnal.narotama.ac.id/index.php/kinerja/article/view/613/358

Khoiri, A., Nulngafan, N., Sunarno, W., \& Sajidan, S. (2019). How is Students' Creative Thinking Skills? An Ethnoscience Learning Implementation. Jurnal Ilmiah 
Pendidikan Fisika Al-Biruni, 8(2), 153-163.

Kotler, Philip, "Manajemen Pemasaran”, Edisi 12 jilid 1, Penerbit PT Indeks Kelompok Gramedia, Jakarta, 2009.

Kusumawardani, N. (2012), "Analisis Pengaruh Proses Belajar Mengajar dan Kualitas Layanan Terhadap Kepuasan Mahasiswa", Tesis S2 Magister Manajemen Universitas Pamulang.

Maholtra, N. K. (2010). Riset Pemasaran Pendekatan Terapan (Jilid 1 \& Jilid 2 edisi keempat), Jakarta: PT Indeks.

Mulyasana, D. (2011). Pendidikan Bermutu dan Berdaya Saing, Bandung: PT Remaja Rosdakarya Offset.

Prastyo, A. T. (2011). Kamus Istilah Pendidikan, Malang: Aditya Media Publishing.

Prihatin, E. (2011). Teori Administrasi Pendidikan, Bandung: Alfabeta.

Rahmayanty, N. (2010). Manajemen Pelayanan Prima, Yogyakarta: Graha Ilmu.

Sudjana. (2005), Metoda Statistika, Edisi 6, Bandung: Penerbit PT Trasito.

Sugiyono. (2005). Metode Penelitian Bisnis, Cetakan 8, Bandung: Penerbit CV Alfabeta.

Sunarsi, D. (2016). Hubungan Pengendalian Diri dengan Prestasi Belajar. Penelitian. Fakultas Ekonomi Universitas Pamulang.

Sunarsi, D. (2016, October). Pengaruh Minat, Motivasi Dan Kecerdasan Kognitif Terhadap Prestasi Belajar (Studi Kasus Pada Mahasiswa Program Studi S-1 Manajemen. Fakultas Ekonomi. Universitas Pamulang. Thn. Akademik 2015-2016). In Proceedings (Vol. 1, No. 1).

Sunarsi, D. (2017). Pengaruh Disiplin, Motivasi, Dan Kompetensi Terhadap Prestasi Belajar (Studi Kasus Pada Mahasiswa Universitas Pamulang, Tangerang Selatan Tahun Akademik 2016-2017). Jurnal Mandiri: Ilmu Pengetahuan, Seni, Dan Teknologi, 1(2), 207-226.

Suryabrata, S. (2010). Metodologi Penelitian, Jakarta: PT Rajagrafindo Persada.

Tjiptono, Fandy, Gregorius dan Dadi Adriana, "Pemasaran Strategik", Penerbit CV Andi Offset, Yogyakarta, 2008.

Umar, Husein, (2010), "Riset Pemasaran dan Prilaku Konsumen”, Penerbit PT Gramedia Pustaka Utama, Bekerjasama dengan Jakarta Business Research Centre (JBRC), Jakarta, .

Wibowo, L. A. (2009). Judul makalah "Strategi Experimental Marketing Perguruan Tinggi" dalam buku Manajemen Corporate \& Strategi Pemasaran Jasa Pendidikan Fokus pada Mutu dan Layanan Prima. Bandung: Penerbit Alfabeta.

Y Kadarusman, D Sunarsi. (2020). Pengaruh Strategi Penetapan Harga Terhadap Peningkatan Jumlah Siswa Pada SMK PGRI Balaraja. JS (Jurnal Sekolah) 4 (3), 213-221

Yuangga, K. D., Jasmani, J., \& Sunarsi, D. (2017). The Influence of Technology Determinism and Technology Literacy on Student Learning Outcomes (On MA Daarul Hikmah Pamulang). PINISI Discretion Review, 1(1), 23-30. 